\title{
Long-term outcomes of single-port laparoscopic myomectomy using a modified suture technique
}

\author{
Mina Kang, MD ${ }^{1, *}$, Jihye Kim, MD ${ }^{2, *}$, Tae-Joong Kim, MD, PhD ${ }^{1}$, Jeong-Won Lee, MD, PhD ${ }^{1}$, \\ Byoung-Gie Kim, MD, PhD' , Duk-Soo Bae, MD, PhD', Chel Hun Choi, MD, PhD ${ }^{1}$ \\ Department of Obstetrics and Gynecology, ${ }^{1}$ Samsung Medical Center, Sungkyunkwan University School of Medicine, Seoul, ${ }^{2}$ Dankook University \\ Hospital, Cheonan, Korea
}

\section{Objective}

To evaluate the long-term outcomes, including the pregnancy outcome and recurrence rate after single-port laparoscopic myomectomy (LM) using a modified suture technique with a Hem-o-lok clip (Choi's LM) and conventional 4-port LM.

\section{Methods}

A retrospective study of patients who underwent Choi's LM $(n=55)$ and 4-port $L M(n=102)$ in a single institutional hospital was conducted. Patients with $<3$ symptomatic myomas sized $<10 \mathrm{~cm}$ each and operated on by a single surgeon were included. Recurrence was confirmed when a myoma measuring $\geq 3 \mathrm{~cm}$ was detected.

\section{Results}

The patients in both groups had similar demographic characteristics. Single (76.4\% vs. $62.7 \%)$ and intramural $(52.7 \%$ vs. $56.9 \%)$ tumors were commonly detected in both groups in the mean diameter $(6.8 \pm 1.5 \mathrm{~cm}$ vs. $7.0 \pm 1.6 \mathrm{~cm}$; $P=0.40$ ). In Choi's LM, 16 patients (29.1\%) needed an additional port; those who were nulliparous and/or had a large leiomyoma more frequently required an additional port ( $P=0.023$ and 0.04 , respectively). During a median follow-up period of 69 months, 17 patients $(7.1 \%$ vs. $14.6 \%)$ had recurrence. The size of dominant myomas at recurrence was significantly smaller in patients who underwent Choi's LM $(3.4 \pm 0.7 \mathrm{~cm}$ vs. $5.7 \pm 2.4 \mathrm{~cm} ; P=0.004)$. All 13 patients in both groups who successfully conceived had a full-term delivery. No major complications occurred during pregnancy.

\section{Conclusion}

Although an additional port was frequently used, the long-term outcomes of patients who experienced recurrence and pregnancy after Choi's LM were acceptable. Considering its usability, Choi's LM is feasible for the treatment of uterine leiomyoma.

Keywords: Laparoscopic myomectomy; Modified suture technique; Pregnancy; Single port; Uterine leiomyoma

\section{Introduction}

Uterine leiomyoma is the most common benign tumor of the female genital tract, affecting approximately $20-50 \%$ of all women. Although hysterectomy is an option for the surgical management of uterine leiomyomas, myomectomy is an attractive alternative for women who desire to preserve fertility $[1,2]$.

Laparoscopic myomectomy (LM) was described in 1979 by Semm [3]; LM has distinct advantages over abdominal myomectomy, including shorter hospital stay, faster recovery, less adhesion, cosmetic advantages, and reduced blood loss [4-6].
Received: 2019.05.19. Revised: 2019.08.24. Accepted: 2019.09.04. Corresponding author: Chel Hun Choi, MD, PhD

Department of Obstetrics and Gynecology, Samsung Medical Center, Sungkyunkwan University School of Medicine, 81 Irwonro, Gangnam-gu, Seoul 06351, Korea E-mail: chelhun.choi@samsung.com https://orcid.org/0000-0002-0199-6669

${ }^{\star}$ These authors contributed equally to this work.

Articles published in Obstet Gynecol Sci are open-access, distributed under the terms of the Creative Commons Attribution Non-Commercial License (http://creativecommons. org/licenses/by-nc/3.0/) which permits unrestricted non-commercial use, distribution, and reproduction in any medium, provided the original work is properly cited.

Copyright $\odot 2020$ Korean Society of Obstetrics and Gynecology 


\section{Obstetrics \& Gynecology Science}

Mina Kang, et al. Long-term outcomes of single port LM

On account of these merits, LM has become a recent trend for the surgical treatment of uterine leiomyoma. With the use of more advanced instruments, such as articulating forceps or barbed suture devices, and increase in the surgeons' experience, surgeons are attempting to minimize the number of abdominal incisions and visible scars; single-port LM (SP-LM) has been introduced and is a rapidly evolving field with this tendency [7-11].

However, technical difficulties are associated with SP-LM when suturing uterine defects because of the collision of instruments, limited number of operating arms, and absence of an assistant arm for maintaining tension. Therefore, barbed suture devices are frequently used during SP-LM procedures because they are easy to use and shorten the operative time [10]. Despite these advantages, the use of residual barbed suture materials has been implicated to cause bowel complications after laparoscopic gynecologic surgery $[12,13]$. Given that bowel complications adversely affect the patients' quality of life, efforts are needed to find alternative suturing methods to repair the uterine defects during SP-LM.

To compensate the limitations of the barbed suture devices, we adopted several modified suture techniques, which included Hem-o-lok clip anchoring, continuous horizontal mattress suturing of the myometrium, and baseball suturing of the uterine serosa in SP-LM (Choi's LM) since 2011 [14]. This retrospective study reported that Choi's LM performed using the modified suture technique was associated with a shorter operative time and less blood loss.

Several studies reported immediate surgical outcomes and provided technical descriptions of the novel suturing technique for SP-LM; in contrast, only a limited number of studies reported the long-term recurrence and pregnancy outcomes of patients who underwent SP-LM.

LM had higher recurrence rate than open myomectomy [15], and a 5-year cumulative recurrence rate of up to $52.9 \%$ had been reported after LM [16].

After myomectomy, uterine rupture and dehiscence are among the life-threatening complications that can possibly occur during pregnancy [17]. In this study, we aimed to investigate the long-term outcomes, including pregnancy outcome and recurrence rate, of patients who underwent Choi's LM as treatment for symptomatic uterine leiomyoma and compare these outcomes with those of patients who underwent conventional multi-port LM (4-port LM).

\section{Materials and methods}

\section{Study population}

In October 2011, with 55 patients who underwent 2-port LM, Choi's LM was introduced in SP-LM using a new modified suture technique. This Choi's LM procedure was performed by a single surgeon ( $\mathrm{CH}$ Choi) who performed over 100 LM procedures per year at Samsung Medical Center.

Patients with $<3$ symptomatic leiomyoma measuring $10 \mathrm{~cm}$ or less on ultrasonography and were eligible for Choi's LM. Patients who fulfilled the inclusion criteria were selected consecutively to undergo this procedure, and data were collected prospectively. The decision to perform this procedure was not influenced by the patient's history of abdominal surgery or type of leiomyoma. Before surgery, the risks were explained to the patient, including the potential need for an additional port during surgery and the risk of uterine rupture in future pregnancies. As a control, all patients who underwent conventional multi-port LM (4-port LM) from January 2008 through November 2010 were included. The inclusion criteria were the same as above.

\section{Data collection}

The following patient characteristics were obtained: age, body mass index (BMI), parity, symptoms resulting from myomas, location and type of largest myomas, and number and diameter of dominant myomas.

During the long-term follow-up, patients were evaluated via ultrasonography every 6 months for the first year and annually thereafter. Leiomyoma recurrence was confirmed when a new leiomyoma measuring $3 \mathrm{~cm}$ or more was detected on ultrasonography. Patients were also asked if they attempted to become pregnant, and all of the obstetric data were collected during the follow-up.

\section{Surgical procedure}

The Choi's LM procedure was described in our previous study [14]. Briefly, using the open Hasson technique, a 2-cm vertical incision was made within the umbilicus, and an extrasmall wound retractor (Alexis; Applied Medical, Rancho Santa Margarita, CA, USA) was inserted into the wound opening. Once it fixed in the opening site, the retractor laterally retracted the sides of the wound opening. A surgical glove with sheaths inserted into 3 fingers was attached to the outer ring of the retractor to maintain pneumoperitoneum. 


\section{Obstetrics \& Gynecology Science}

Vol. 63, No. 2, 2020

After enucleation of the leiomyoma, the uterine parenchymal defect was closed laparoscopically in a double layer. A 1-0 Vicryl suture (Polyglactin; Ethicon, Somerville, NJ, USA) on a large curved needle was then used to make a deep and wide bite. Before suturing, the Vicryl suture was tied with a Hem-o-lok clip, which acts as anchor on the tail of the continuous suture and was the starting point of the suture site (Fig. 1A). Basically, all sutures were completed with one continuous suture using a double layer technique. First, a horizontal mattress suture with a deep and wide bite was performed at the bottom of the defect to attach the myometrium closely and for hemostasis (Fig. 1B and C). In the case of large myometrial defects, additional horizontal mattress sutures were performed in a continuous manner. Following the horizontal mattress suture, a baseball suture was performed in the opposite direction to close the myometrium and serosa tightly (Fig. 1D and E). In the baseball suture, the edges of the uterine defect were approximated with introflexion stitches (myometrium/serosa-serosa/myometrium direction) at $1.5-\mathrm{cm}$ increments from the side of the incision and held tightly with articulating grasper to secure tension. After completing the baseball suture, 2 Hem-o-lok clips were applied and pushed with maximal tension to secure the suture (Fig. 1F). The knot was tightly fixed immediately, decreasing the risk of knot loosening during interrupted knot typing. Up to 3 Hem-o-lok clips were used during this procedure.

If the surgery was difficult to perform on a single-port platform or when prolonged operation was anticipated, the surgeon decided whether to create an additional 5-mm port in the suprapubic area at any time during the surgery. To perform a 2-port LM, a 5-mm ancillary trocar was inserted 2 fingerbreadths above the symphysis pubis. Lastly, the resected leiomyoma was wrapped with an endopouch and removed via the umbilical wound by cutting it into smaller pieces using a knife.

\section{Statistical analyses}

Descriptive statistics were used to analyze categorical and continuous variables. Continuous variables were compared using the Mann-Whitney U-test or Student's $t$-test. Fisher's exact test, $\chi^{2}$ test, or logistic regression test was used to analyze categorical variables. Recurrence rates were compared using Kaplan-Meier curve. Statistical analyses were performed using SPSS version 25.0 (SPSS, Chicago, IL, USA). A
$P$-value of $\leq 0.05$ was considered significant, and all $P$-values were 2 sided.

\section{Results}

Of 184 patients who underwent Choi's LM and 4-port LM, 27 were excluded because of the size $(>10 \mathrm{~cm})$ or number $(\geq 3)$ of myomas. Of 157 patients who fulfilled the inclusion criteria, 55 underwent Choi's LM and 102 underwent 4-port LM.

A
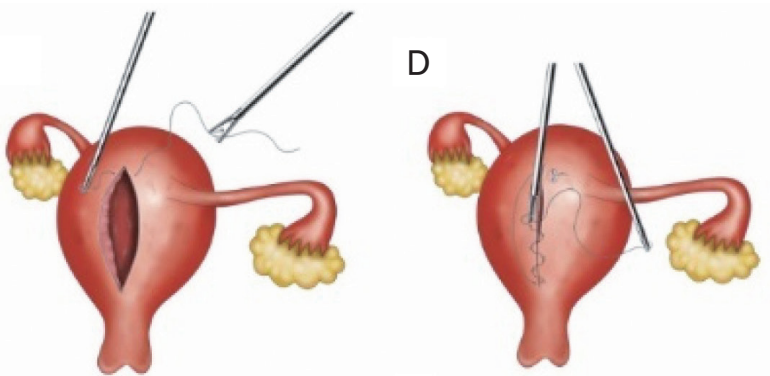

B

$E$

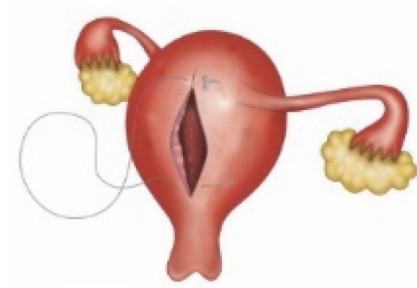

C

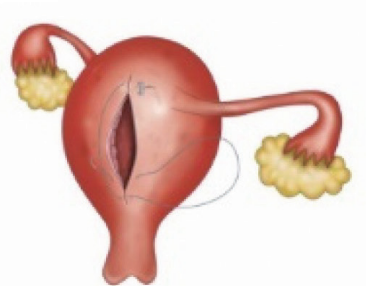

$\mathrm{F}$
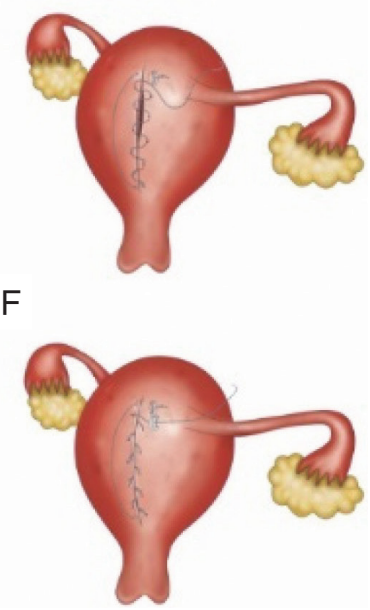

Fig. 1. Single-port laparoscopic myomectomy (LM) with a modified suture technique with a Hem-o-lok clip (Choi's LM). (A) The 1-0 Vicryl suture was tied with a Hem-o-lok clip, which acts as an anchor on the tail of the continuous suture that is the starting point of the suture site. $(B, C) A$ horizontal mattress suture with a deep and wide bite was performed at the bottom of the defect to attach the myometrium closely. (D) A baseball suture was performed in the opposite direction to approximate the myometrium and serosa tightly, while the grasper was used and pushed with maximal tension to cinch down on the last suture site to secure the suture. (E) The same procedures were continuously repeated. (F) The Hem-o-lok clip was used to cinch down on the suture site and secure the knot tightly. 


\section{Obstetrics \& Gynecology Science}

Mina Kang, et al. Long-term outcomes of single port LM

The detailed patient demographic data and characteristics of myomas are shown in Table 1. Patients' age, BMI, parity, and symptoms related to myomas were similar in the 2 groups. The mean age of Choi's group was $39.4 \pm 6.2$ years (range, 27-52 years), while that of the 4-port LM group was $38.6 \pm 5.7$ years (range, $26-55$ years) $(P=0.41$, respectively). Nineteen patients (34.5\%) in the Choi's LM group and 31 $(30.4 \%)$ in the 4 -port $\operatorname{LM}(P=0.56)$ were nulliparous. The initial preoperative indications were menorrhagia (40\% vs. $45.1 \%)$, compression symptoms (38.2\% vs. $28.4 \%)$, and

Table 1. Demographic data of the patients in the Choi's laparoscopic myomectomy (LM) and 4-port LM group

\begin{tabular}{|c|c|c|c|}
\hline Variables & $\begin{array}{l}\text { Choi's LM } \\
(n=55)\end{array}$ & $\begin{array}{l}\text { 4-port LM } \\
(n=102)\end{array}$ & $P$-value ${ }^{\text {a) }}$ \\
\hline Age (yr) & $39.4 \pm 6.2$ & $38.6 \pm 5.7$ & 0.41 \\
\hline BMI $\left(\mathrm{kg} / \mathrm{m}^{2}\right)$ & $22.5 \pm 3.8$ & $22.9 \pm 3.3$ & 0.49 \\
\hline Parity & & & 0.56 \\
\hline Nulliparous & $19(34.5)$ & $31(30.4)$ & \\
\hline Multiparous & $36(65.5)$ & $71(69.6)$ & \\
\hline Symptoms & & & 0.29 \\
\hline Menorrhagia & $22(40.0)$ & $46(45.1)$ & \\
\hline Compression & $21(38.2)$ & $29(28.4)$ & \\
\hline Pain & $11(20.0)$ & $27(26.5)$ & \\
\hline Infertility & $1(1.8)$ & 0 & \\
\hline $\begin{array}{l}\text { Wall where main myoma } \\
\text { originated }\end{array}$ & & & 0.22 \\
\hline Anterior & $26(47.3)$ & $43(42.2)$ & \\
\hline Posterior & $13(23.6)$ & $34(33.3)$ & \\
\hline Fundal & $7(12.7)$ & $20(19.6)$ & \\
\hline Lateral & $9(16.4)$ & $5(4.9)$ & \\
\hline $\begin{array}{l}\text { Type of largest myoma per } \\
\text { patient }\end{array}$ & & & 0.34 \\
\hline 1-2 (submucosal) & $7(12.7)$ & $8(7.8)$ & \\
\hline 3 (EM involvement) & $7(12.7)$ & $4(3.9)$ & \\
\hline 4-5 (intramural) & $29(52.7)$ & $58(56.9)$ & \\
\hline 6-7 (subserosal) & $12(21.8)$ & $32(31.4)$ & \\
\hline Diameter of main fibroid (cm) & $6.8 \pm 1.5$ & $7.0 \pm 1.6$ & 0.40 \\
\hline \multicolumn{4}{|l|}{ No. of myoma per patient } \\
\hline 1 & $42(76.4)$ & $64(62.7)$ & 0.11 \\
\hline $2<$ & $13(23.6)$ & $38(37.3)$ & \\
\hline
\end{tabular}

Data are shown as mean \pm standard deviation or number (\%).

BMl, body mass index; EM, endometrium.

a) The $P$-value was determined using $\chi^{2}$ test, Fisher's exact test, or Student's t-test. pelvic pain (20.0\% vs. $26.5 \%)$.

There was no significant difference in the characteristics of the myomas between the 2 groups. Forty-two women (76.4\%) in the Choi's LM group and 64 women $(62.7 \%)$ in the 4-port LM group had a single leiomyoma $(P=0.11)$. The most common type of leiomyoma was intramural type (3-5; $36[65.4 \%]$ vs. 62 [60.8\%]), followed by subserosal type (6-7; $12[21.8 \%]$ vs. $32[31.4 \%])$ and submucosal type (1-2; $7[12.7 \%]$ vs. $8[7.8 \%] ; P=0.34)$. For both groups, anterior wall $(26[47.3 \%]$ vs. 43 [42.2\%]) was the most common location of myomas. Mean diameter of the largest leiomyoma was also similar between 2 groups $(6.8 \pm 1.5 \mathrm{~cm}$ [range, $5.0-9.9 \mathrm{~cm}$ ] vs. $7.0 \pm 1.6 \mathrm{~cm}$ [range, $5.0-9.9 \mathrm{~cm}])$, as measured on ultrasonography $(P=0.11)$.

In Choi's LM group, 16 (29.1\%) patients required an additional port to achieve meticulous repair of the uterine defect. We compared the clinical factors associated with the need for an additional port. In multivariate analysis (Table 2), clinical factors associated with additional port insertion were diameter of the main fibroid and parity $(P=0.04$ and 0.023 , respectively). Multiparous women did not require an additional port. Type and location of leiomyoma were not associated with the need for an additional port. However, there is a possibility that the cases of patients requiring an additional port were more complicated, which can lead to longer operating time, larger blood loss, and/or longer hospital stay.

Within a median follow-up of 69 months, 17 patients (4 [7.1\%] vs. 13 [14.6\%]) had myoma recurrence $(P=0.292)$ (Table 3). In Choi's LM group, most of the patients had solitary-type (4 [75\%]) and intramural-type myomas (4 [100\%]). In contrast, the 4-port LM group had multiple (8 [61.5\%])

Table 2. Logistic regression results for predicting additional port insertion in Choi's laparoscopic myomectomy

\begin{tabular}{lccc}
\hline Patient characteristics & OR & 95\% Cl & $\boldsymbol{P}_{\text {-value }}{ }^{\text {a) }}$ \\
\hline $\begin{array}{l}\text { Multiparous } \\
\begin{array}{l}\text { Wall where main fibroids } \\
\text { originated }\end{array}\end{array}$ & 0.185 & $0.043-0.789$ & 0.023 \\
Anterior & - & - & 0.411 \\
Posterior & 0.362 & $0.063-2.095$ & 0.257 \\
Fundus & 0.658 & $0.082-5.293$ & 0.658 \\
Lateral & 3.469 & $0.630-33.463$ & 0.282 \\
Diameter of main fibroid & 1.759 & $1.027-3.014$ & 0.040 \\
\hline
\end{tabular}

$\mathrm{Cl}$, confidence interval; $\mathrm{OR}$, odds ratio.

a) The $P$-value was determined using Logistic regression test. 


\section{Obstetrics \& Gynecology Science}

Vol. 63, No. 2, 2020

and more various types of myomas $(P=0.25)$. The size of dominant myomas at recurrence was significantly smaller in Choi's LM group $(3.4 \pm 0.7 \mathrm{~cm}$ [range, $3.0-3.9 \mathrm{~cm}$ ] vs. $5.7 \pm 2.4 \mathrm{~cm}$ [range, $3.3-11.0 \mathrm{~cm}$ ]; $P=0.004$ ). The KaplanMeier curve (Fig. 2) showed similar 5-year cumulative recurrence rate in both groups.
The pregnancy outcomes of the 2 groups are summarized in Table 4. Four patients in the Choi's LM group and 9 in the 4-port LM group successfully conceived, and all of had fullterm delivery. Three patients had 2 pregnancies during the follow-up period. Two patients in the Choi's LM group and 1 in the 4-port LM group had a successful vaginal delivery

Table 3. Characteristics of recurrence after myomectomy

\begin{tabular}{|c|c|c|c|}
\hline Characteristics & Choi's LM $(n=4)$ & 4-port LM $(n=13)$ & $P$-value ${ }^{\text {a) }}$ \\
\hline \multicolumn{4}{|l|}{ No. of myomas at recurrence } \\
\hline 1 & $3(75.0)$ & $5(38.5)$ & 0.250 \\
\hline$>2$ & $1(25.0)$ & $8(61.5)$ & - \\
\hline \multicolumn{4}{|c|}{ Myoma type at recurrence, according to FIGO classification } \\
\hline 1-2 (submucosal) & 0 & $1(7.7)$ & 0.430 \\
\hline 3 (intramural, EM involved) & 0 & $2(15.4)$ & - \\
\hline $4-5$ (intramural) & $4(100.0)$ & $6(46.2)$ & - \\
\hline $6-7$ (subserosal) & 0 & $4(30.8)$ & - \\
\hline Myoma location at recurrence & & & 1.000 \\
\hline Anterior & $1(25.0)$ & $5(38.5)$ & \\
\hline Posterior & $1(25.0)$ & $4(30.8)$ & \\
\hline Fundus & $2(50.0)$ & $4(30.8)$ & \\
\hline Lateral & 0 & 0 & \\
\hline Size of myoma at recurrence $(\mathrm{cm})$ & & & 0.004 \\
\hline Mean \pm standard deviation & $3.4 \pm 0.7$ & $5.7 \pm 2.4$ & \\
\hline Median (range) & $3.3(3-3.9)$ & $4.8(3.3-11)$ & \\
\hline
\end{tabular}

EM, endometrium; FIGO, Federation of Gynecology and Obstetrics; LM, laparoscopic myomectomy.

${ }^{a}$ The $P$-value are represented as myoma recurrence $(P=0.292)$.

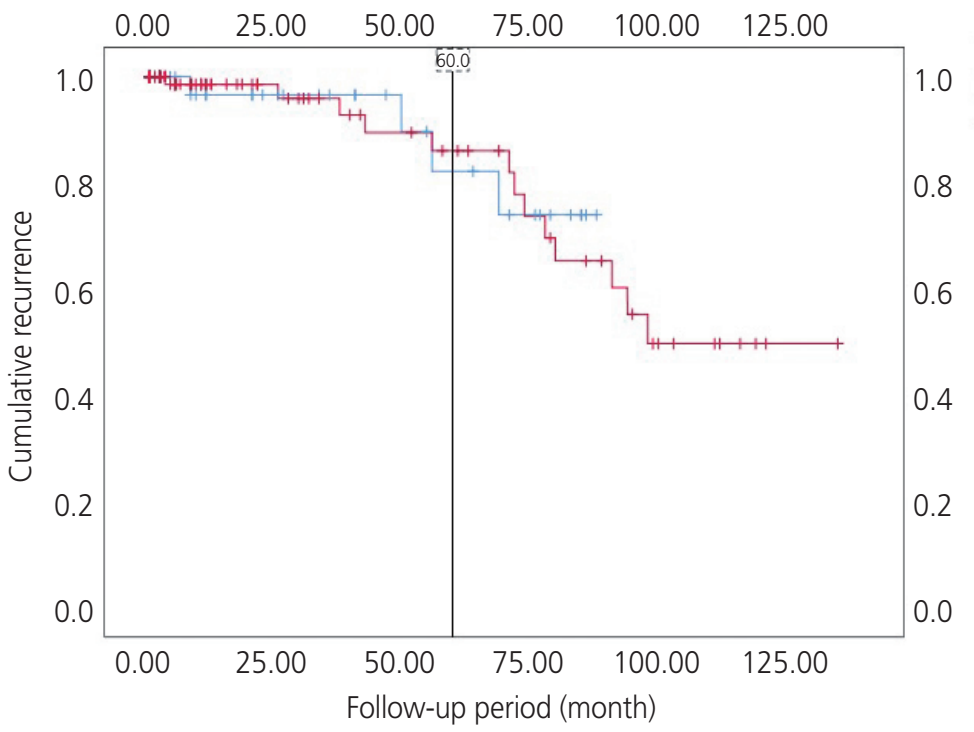

$\neg$ SP-LM

$\neg$ 4-Port LM

+ SP-LM censored

+ 4-Port LM censored
Fig. 2. Kaplan-Meier curve showing similar cumulative recurrence rate $(P=0.835)$. Probability of 5 -year recurrence-free survival of patients: Choi's LM (82.2\%) vs. 4-port LM (86.0\%). SP, single-port; LM, laparoscopic myomectomy. 


\section{Obstetrics \& Gynecology Science}

Mina Kang, et al. Long-term outcomes of single port LM

Table 4. Pregnancy outcomes of patients after myomectomy

\begin{tabular}{|c|c|c|c|c|c|}
\hline Case Number & Age at LM (yr) & $\begin{array}{l}\text { Operation to deliv- } \\
\text { ery time, (mon) }\end{array}$ & GA at delivery (wk) & $\begin{array}{l}\text { Complication dur- } \\
\text { ing pregnancy }\end{array}$ & $\begin{array}{l}\text { Abnormal findings at } \\
\text { Caesarean section }\end{array}$ \\
\hline \multicolumn{6}{|l|}{ Choi's LM } \\
\hline $1-1$ & 30 & 16 & 39.0 & - & - \\
\hline $1-2$ & - & 84 & 39.0 & - & Adhesion \\
\hline 2 & 27 & 19 & 38.2 & - & - \\
\hline 3 & 32 & 36 & NA & - & NFSD \\
\hline 4 & 27 & 55 & NA & - & NFSD \\
\hline \multicolumn{6}{|l|}{ 4-port-LM } \\
\hline $1-1$ & 29 & 11 & 36.5 & - & - \\
\hline $1-2$ & - & 34 & 38.4 & - & Adhesion \\
\hline $2-1$ & 33 & 12 & 39.0 & - & Adhesion \\
\hline $2-2$ & - & 41 & 38.6 & - & Adhesion \\
\hline 3 & 28 & 20 & 38.4 & - & - \\
\hline 4 & 34 & 23 & 38.1 & - & - \\
\hline 5 & 30 & 20 & NA & - & NFSD \\
\hline 6 & 33 & 54 & 38.1 & - & - \\
\hline 7 & 32 & 64 & NA & - & - \\
\hline 8 & 28 & 10 & NA & - & - \\
\hline 9 & 33 & 18 & NA & - & Adhesion \\
\hline
\end{tabular}

LM, laparoscopic myomectomy; GA, gestational age; NFSD, normal full-term vaginal delivery; NA, not available (the exact GA was not available if delivered outside).

with no serious complications. They developed the same type of myoma (pedunculated subserosal type 7) before surgery. No major complications (such as uterine rupture or dehiscence) related to LM occurred during pregnancy. No abnormal findings, other than mild adhesion, were reported during cesarean section in both groups.

\section{Discussion}

This study suggests that SP-LM using a modified suture technique (Choi's LM) was a possible alternative in selected patients with a symptomatic leiomyoma measuring $10 \mathrm{~cm}$ or less and fewer than 3 leiomyomas considering the longterm outcome. Although 16 patients (29.1\%) needed an additional port, the perioperative outcomes of this study were comparable to those of previous studies using barbed suture devices for SP-LM [18-20].

Patients who were nulliparous and/or had a large leiomyoma were more likely to require an additional port. This result can be explained by the meticulous suturing of the myometrium for nulliparous women. Although cosmetic outcomes and surgical outcomes were important, meticulous suture was more important for nulliparous women who are planning to become pregnant in the future. Myomectomy is a fertility-preserving surgery for nulliparous women but may lead to uterine rupture during pregnancy. Single-layered closure of uterine wall defect and frequent use of electrocautery are risk factors of uterine rupture [17]. Surgeons who perform single-port myomectomy should pay special attention on suturing the myometrium in nulliparous women. Although Choi's LM had no adverse pregnancy outcomes related with the insertion of Hem-o-lok clips in situ, the data used in this study were too insufficient.

Long-term follow-up data of our study showed that the recurrence rate was acceptable compared with that of previous studies $[16,21]$. Two groups had similar patient and myoma characteristics identified as risk factors: age, size of myoma, and number of myoma [16]. Peri- and postmenopausal patients with single myoma had the lowest recurrence rate 


\title{
Obstetrics \& Gynecology Science
}

\author{
Vol. 63, No. 2, 2020
}

after undergoing laparoscopy and can be considered as the best candidate for SP-LM [22].

Several studies have reported the benefits of SP-LM. SPLM provides better cosmetic results because of the relatively hidden umbilical scar [23]. Although $29.1 \%$ of patients in this study required an additional port, the port was located at 2 finger widths above the symphysis pubis, alleviating cosmetic concerns. Another possible benefits of SP-LM using the glove technique are as follows: less common subcutaneous emphysema, port-site wound infection, and hemorrhage because of the tamponade effect of the wound retractor [24]. In this study, no wound-related complications, such as hematoma, herniation, or wound dehiscence, were reported. Furthermore, the glove-wound retractor system provided a higher degree of freedom for operative maneuvers, making laparoscopic suturing easier to perform. Additionally, leiomyoma was wrapped in an endopouch and extracted through a trans-umbilical knife morcellation, which lessened the risk of leiomyoma seeding by mechanical morcellation [25].

Despite these advantages, laparoscopic repair of uterine defects through a single port remains arduous and requires greater surgical skill because of the limited of instrument movement. Besides, the quality of uterine defect suture is important in myomectomy considering the perioperative outcomes and future pregnancy. Therefore, in order to reduce tissue ischemia and necrosis, it is crucial to ensure that the tensile strength is evenly distributed over the entire length of the uterine defect. When suturing is insufficient, oozing from the uterine defect, formation of dead space, and subsequent hematoma formation at the incision site increase the risk of postoperative wound infection and adhesion [26,27]. Recently, barbed suture devices have been widely used in minimally invasive surgery because they allow continuous wound closure with even distribution of tensile strength and are easy to use as there is no need to tie knots $[27,28]$. However, in some cases, the exposed barbed suture material caused entanglement and/or erosion of bowel or mesentery, resulting in bowel complications, including bowel obstruction, strangulation, or volvulus, and thus requiring surgical intervention $[12,13]$. To eliminate these complications, previous case reports recommended cutting the barbed suture devices flushed with the myometrium or using the conventional suture material for repair of the seromuscular layer of the myometrium [13]. Besides, barbed sutures cannot be reversed, and fine-tuning of tension can be difficult. Moreover, this type of suture device is unavailable in some countries, and the cost can be a problem. However, in Choi's LM, we repaired the uterine defect with Vicryl sutures, which are commonly used in laparotomy or laparoscopic surgery. Unlike the barbed suture devices, tension can be modified repeatedly with Choi's LM if needed, and once the suture is passed, additional Hem-o-lok clips could be applied on the suture site repeatedly to maintain tension, if required. This procedure is very simple compared with the conventional interrupted suturing method and is effective for hemostasis.

There were several limitations in our study. First, the number of cases was small and many patients required an additional port. However, surgeons who perform SP-LM should keep in mind that the purpose of the operation is not to use a single-port approach, but to successfully perform a myomectomy. Therefore, surgeons should not hesitate to convert from a single-port system to a 2-port system if necessary to achieve complete myomectomy. Moreover, we expect that the conversion rate to a 2-port system will decrease with technical improvements and increase in surgeon's experience. Second, a greater limitation is the lack of control group. Hence, futures studies should provide a comparison between the new suture technique and the conventional suture method. Lastly, although the nonabsorbable Hem-o-lok polymer ligation clip has been widely used in laparoscopic surgery [29-35], the Hem-o-lok clips present on the uterine surface may lead to foreign body reaction since the Hem-o-lok clips have adhesive potential.

In conclusion, recent trends in the surgical treatment of uterine leiomyoma include minimally invasive options, such as single-port surgery. However, repairing the uterine defect using a single-port system is one of the most challenging and time-consuming steps. This study showed that SP-LM using a modified suture technique with a Hem-o-lok clip (Choi's LM) is a feasible and safe alternative in select patients. However, a large prospective study is required to conclusions.

\section{Conflict of interest}

No potential conflict of interest relevant to this article was reported. 


\section{Obstetrics \& Gynecology Science}

Mina Kang, et al. Long-term outcomes of single port LM

\section{Ethical approval}

This study was approved by the Institutional Review Board of Samsung Medical Center (file No. 2019-08-063-002).

\section{References}

1. Sami Walid M, Heaton RL. The role of laparoscopic myomectomy in the management of uterine fibroids. Curr Opin Obstet Gynecol 2011;23:273-7.

2. Wise LA, Laughlin-Tommaso SK. Epidemiology of uterine fibroids: from menarche to menopause. Clin Obstet Gynecol 2016;59:2-24.

3. Semm K. New methods of pelviscopy (gynecologic laparoscopy) for myomectomy, ovariectomy, tubectomy and adnectomy. Endoscopy 1979;11:85-93.

4. Di Gregorio A, Maccario S, Raspollini M. The role of laparoscopic myomectomy in women of reproductive age. Reprod Biomed Online 2002;4 Suppl 3:55-8.

5. Gutt CN, Oniu T, Schemmer P, Mehrabi A, Büchler MW. Fewer adhesions induced by laparoscopic surgery? Surg Endosc 2004;18:898-906.

6. Jain N. Multiple layer closure of myoma bed in laparoscopic myomectomy. J Gynecol Endosc Surg 2011;2:43-6.

7. Ramesh B, Vidyashankar M, Bharathi B. Single incision laparoscopic myomectomy. I Gynecol Endosc Surg 2011;2:61-3.

8. Han CM, Lee CL, Su H, Wu PJ, Wang CJ, Yen CF. Singleport laparoscopic myomectomy: initial operative experience and comparative outcome. Arch Gynecol Obstet 2013;287:295-300.

9. Kim SK, Lee JH, Lee JR, Suh CS, Kim SH. Laparoendoscopic single-site myomectomy versus conventional laparoscopic myomectomy: a comparison of surgical outcomes. J Minim Invasive Gynecol 2014;21:775-81.

10. Song T, Kim TJ, Kim WY, Lee SH. Comparison of barbed suture versus traditional suture in laparoendoscopic single-site myomectomy. Eur J Obstet Gynecol Reprod Biol 2015;185:99-102.

11. Lee D, Kim SK, Kim K, Lee JR, Suh CS, Kim SH. Advantages of single-port laparoscopic myomectomy compared with conventional laparoscopic myomectomy: a randomized controlled study. J Minim Invasive Gynecol 2018;25:124-32.
12. Buchs NC, Ostermann S, Hauser J, Roche B, Iselin CE, Morel P. Intestinal obstruction following use of laparoscopic barbed suture: a new complication with new material? Minim Invasive Ther Allied Technol 2012;21:369-71.

13. Lee ET, Wong FW. Small bowel obstruction from barbed suture following laparoscopic myomectomy-a case report. Int J Surg Case Rep 2015;16:146-9.

14. Choi CH, Kim TH, Kim SH, Choi JK, Park JY, Yoon A, et al. Surgical outcomes of a new approach to laparoscopic myomectomy: single-port and modified suture technique. J Minim Invasive Gynecol 2014;21:580-5.

15. Kotani $Y$, Tobiume T, Fujishima R, Shigeta M, Takaya H,

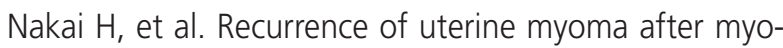
mectomy: open myomectomy versus laparoscopic myomectomy. J Obstet Gynaecol Res 2018;44:298-302.

16. Yoo EH, Lee Pl, Huh CY, Kim DH, Lee BS, Lee JK, et al. Predictors of leiomyoma recurrence after laparoscopic myomectomy. J Minim Invasive Gynecol 2007;14:690-7.

17. Bujold E, Bujold C, Hamilton EF, Harel F, Gauthier RJ. The impact of a single-layer or double-layer closure on uterine rupture. Am J Obstet Gynecol 2002;186:1326-30.

18. Song T, Kim TJ, Lee SH, Kim TH, Kim WY. Laparoendoscopic single-site myomectomy compared with conventional laparoscopic myomectomy: a multicenter, randomized, controlled trial. Fertil Steril 2015;104:1325-31.

19. Yuk JS, Ji HY, Kim KH, Lee JH. Single-port laparoscopically assisted-transumbilical ultraminilaparotomic myomectomy (SPLA-TUM) versus single port laparoscopic myomectomy: a randomized controlled trial. Eur J Obstet Gynecol Reprod Biol 2015;188:83-7.

20. Lee SW, Park EK, Lee SJ, Lee KH. Comparison study of consecutive 100 cases of single port vs. multiport laparoscopic myomectomy; technical point of view. J Obstet Gynaecol 2017;37:616-21.

21. Doridot V, Dubuisson JB, Chapron C, Fauconnier A, Babaki-Fard K. Recurrence of leiomyomata after laparoscopic myomectomy. J Am Assoc Gynecol Laparosc 2001;8:495-500.

22. Radosa MP, Owsianowski Z, Mothes A, Weisheit A, Vorwergk J, Asskaryar FA, et al. Long-term risk of fibroid recurrence after laparoscopic myomectomy. Eur J Obstet Gynecol Reprod Biol 2014;180:35-9.

23. Greaves N, Nicholson J. Single incision laparoscopic surgery in general surgery: a review. Ann R Coll Surg Engl 2011;93:437-40. 


\section{Obstetrics \& Gynecology Science}

Vol. 63, No. 2, 2020

24. Lee YY, Kim TJ, Kim CJ, Kang H, Choi CH, Lee JW, et al. Single-port access laparoscopic-assisted vaginal hysterectomy: a novel method with a wound retractor and a glove. J Minim Invasive Gynecol 2009;16:450-3.

25. Kim YW, Park BJ, Ro DY, Kim TE. Single-port laparoscopic myomectomy using a new single-port transumbilical morcellation system: initial clinical study. J Minim Invasive Gynecol 2010;17:587-92.

26. Rossetti A, Sizzi O, Chiarotti F, Florio G. Developments in techniques for laparoscopic myomectomy. JSLS 2007; 11:34-40.

27. Greenberg JA, Goldman RH. Barbed suture: a review of the technology and clinical uses in obstetrics and gynecology. Rev Obstet Gynecol 2013;6:107-15.

28. Greenberg JA, Einarsson JI. The use of bidirectional barbed suture in laparoscopic myomectomy and total laparoscopic hysterectomy. J Minim Invasive Gynecol 2008; 15:621-3.

29. Ates M, Dirican A, Ince V, Ara C, Isik B, Yilmaz S. Comparison of intracorporeal knot-tying suture (polyglactin) and titanium endoclips in laparoscopic appendiceal stump closure: a prospective randomized study. Surg Laparosc Endosc Percutan Tech 2012;22:226-31.
30. Delibegović S. The use of a single Hem-o-lok clip in securing the base of the appendix during laparoscopic appendectomy. J Laparoendosc Adv Surg Tech A 2012;22:85-7.

31. Hanssen A, Plotnikov S, Dubois R. Laparoscopic appendectomy using a polymeric clip to close the appendicular stump. JSLS 2007;11:59-62.

32. Janczak D, Merenda M, Litarski A, Wieraszko A, Rać J. Use of polymeric clips in laparoscopic appendectomy. Polim Med 2011;41:19-23.

33. Izaki H, Fukumori T, Takahashi M, Nakatsuji H, Oka N, Taue $\mathrm{R}$, et al. Clinical research of renal vein control using Hem-o-lok clips in laparoscopic nephrectomy. Int J Urol 2006;13:1147-9.

34. Kapoor R, Singh KJ, Suri A, Dubey D, Mandhani A, Srivastava $A$, et al. Hem-o-lok clips for vascular control during laparoscopic ablative nephrectomy: a single-center experience. J Endourol 2006;20:202-4.

35. Ponsky L, Cherullo E, Moinzadeh A, Desai M, Kaouk J, Haber GP, et al. The Hem-o-lok clip is safe for laparoscopic nephrectomy: a multi-institutional review. Urology 2008;71:593-6. 